\begin{tabular}{|c|c|}
\hline Title & $\begin{array}{l}\text { A ccommodation and resistance in Hokkaido hip hop practitioners: A n ethnographic analysis of Generation Resignation } \\
\text { in post-growth Japan }\end{array}$ \\
\hline Author(s) & Klien, Susanne \\
\hline Citation & $\begin{array}{l}\text { Ethnography, 23(1), 83-103 } \\
\text { https://doi.org/10.1177/1466138120907339 }\end{array}$ \\
\hline Issue Date & 2020 \\
\hline Doc URL & http://hdl .handle.net/2115/77043 \\
\hline Rights & $\begin{array}{l}\text { Klien, Susanne. "A ccommodation and Resistance in Hokkaido Hip Hop Practitioners: An Ethnographic A nalysis of } \\
\text { Generation Resignation in Post-Growth Japan.", Ethnography. Copyright @ } 2020 \text { SA GE Publications. DOI: } \\
10.1177 / 1466138120907339 \text {. }\end{array}$ \\
\hline Type & article (author version) \\
\hline File Information & A ccommodation and resistance_Ethnography paper_20200128.pdf \\
\hline
\end{tabular}

Instructions for use 


\section{Accommodation and resistance in Hokkaido hip hop practitioners: An ethnographic analysis of Generation Resignation in post-growth Japan}

Drawing on ethnographic fieldwork conducted between October 2013 and October 2017 in Hokkaido, northern Japan, this paper explores the trajectories of individuals engaging in hip hop music. Participant observation and narratives indicate that the majority of individuals work as regular members of society (shakaijin) and only pursue hip hop in their free time. The paper highlights the intricate entanglement of individuals in subordination to mainstream values despite their references to elements of resistance. I contend that in contrast to previous generations of hip hoppers who chose to lead lives of open resistance to mainstream values, contemporary youth who largely belong to the "Generation Resignation" (satori sedai) prefer to engage in 'disguised forms of resistance' (Vinthagen/Johannsson 2013:25) or 'ambiguous resistance' (Rosenberger 2013) rather than overt contestation of societal conventions.

\section{Keywords}

Resistance, hip hop, youth culture, neoliberalism, Japan, social change, generational change, Generation Resignation

\section{Introduction}

Hip hop - generally understood as the four elements of DJing (including scratching, a turntablist technique of moving a vinyl record back and forth on a turntable to produce percussive sounds), MCing, breaking (also referred to as Bboying) and graffiti (Persley 2015: 85) - tends to be depicted as a 'culture that proposes resistance to oppression and domination but has now become a commercial fad dominated by corporate elites' (Rose 2008 cited in Vito 2015: 395-6). However, rather than perceiving the socioeconomic context of hip hop as a dichotomical bind between often romanticized resistance and dismissed mainstream, recent scholars have called on to address hip-hop "as a complex and incomplete object of struggle bounded by a dialectical process of complicity and resistance" (Maxwell 2009: 133). Similarly, Vito emphasizes the necessity to "follow the lead of those academics who are uncovering these diverse pockets of hip-hop culture both in the US and globally in order to obtain a rich understanding of its complexities and contradictions" (Vito 2015:408). Persley defines hip hop as "a space to resist the status 
quo and to re-imagine racial, social, and cultural identifications" (Persley 2015: 86). This paper echoes the role of hip hop as vehicle of resistance and reimagination; specifically, it presents ethnographic portraits how individuals who engage in hip hop make sense of their increasingly fragmented post-growth worlds. Importantly, Manabe's point about hip hop in Japan having been used as vessels by both neo-nationalist and left-wing stakeholders needs to be kept in mind in this context (2015: 252). Furthermore, David Z. Morris observed that "all of the artists in Japan's hugely diverse hip hop universe deal with divided selves, divided situations, divided practices" (2010: 42). It is these divided selves, situations and practices in hip hop practitioners that are the main research interest of this paper. This focus on the inconsistencies in subjectivities rather than the commonly assumed clearly defined, bounded selves allows for the sharper analytical lens required for understanding neoliberal post-growth societies which are generally characterized by deeply paradoxical modes of behaviour such as greater competition, yet more social engagement (Han 2019: 21). The practices and narratives of individual hip hop practitioners in contemporary Japan confirm hip hop as a "site of contestation, struggle and reflection on the current state of our society" (Vito 2015: 404). This paper builds on previous hip hop studies that have highlighted the ambivalence ingrained in the genre (Maxwell 2009, Morris 2010, Lamotte 2014, Vito 2015). It provides insights into the role of hip hop as a multi-faceted vehicle of simultaneous social engagement and withdrawal by members of a materially and emotionally saturated post-growth society.

Second, previous research into hip hop in Japan has primarily focused on the local appropriations of a global form of music and style. In contrast, this paper examines recent hip hop in northern Japan as a complex - and often contradictory - form of societal engagement ranging from withdrawal to covert resistance by members of a materially saturated post-growth society. Rather than focusing exclusively on hip hop as a tool of achieving social change, this paper approaches hip hop as an instrument for practitioners to cope with uncertainties in their daily lives - "short-term survival and the long-term future," as Schneidermann puts it (2014: 94).

"If it is someone who has no clear interest in hip hop, I definitely wouldn't talk about hip hop. Why? It makes me feel ashamed as it carries such a negative image.” (M, 25) "I only go to clubs if I have to perform myself as a DJ. I am not interested in the social 
relations with other people in the scene. And they don't play the music I like either." (M, 36)

Both of these statements by hip hop practitioners of varying age cohorts indicate social introversion and reluctance to openly discuss values and policies in contemporary Japanese society. These statements also indicate that "there is no clear boundary between scenes and a 'hegemonic' social order" (Haenfler 2014: 13) and that alleged subcultures inherently coopt the perceptions of 'mainstream' society in the way they relate to and describe their own subcultural practices. Drawing on Vito's and Maxwell's idea of the coexistence of cooptation and resistance in hip-hop practices, this paper contends that contemporary appropriations of this musical genre and lifestyle in northern Japan provide intriguing insights into the lived experiences, values and attitudes of the emerging Generation Resignation (satori sedai). Younger representatives of hip hop who mostly belong to the Generation Resignation born after 1980 tend to work in company jobs or as temporary contract workers. This Japanese neologism emerged in 2013 and denotes young Japanese who seem to have achieved a Buddhist enlightened state lacking any material desires, but are also devoid of hope. Socially introverted, representatives of this generation tend to be disinterested in travelling abroad and generally aspire to minimize their stress levels. Having little interest in material affluence, they mostly wish to get by with the money required to cover their basic needs.

The majority of my interviewees concede that they lead double lives, pretending to be 'corporate slaves' (shachiku in Japanese, literally 'company cattle') during the day and performing as drop outs by night and during the weekend. Presenting empirical data collected since October 2013, I contest that recent appropriations of hip-hop in northern Japan provide us with valuable insight into negotiations of work and life in a society that seems characterized by convenience, de-growth and resignation. Most practitioners come from middle-class backgrounds, grew up in households with housewife mothers and salaryman fathers and as shown in the above statement, are reluctant to be openly associated with hip hop due to its associations with crime and violence by Japanese media and the general public. Those who are married and have families tend not to share their leisure interest with them. Unsurprisingly, many seem to have little interest in the scene beyond the music, as illustrated by the second statement at the beginning of this section. The majority engages in their musical interest only on weekends and in their free time 
since they often work full-time in corporate jobs. There is little talk of reclaiming public space or creating autonomous spaces, little 'aspirational focus' (Pieterse 2010); the few skaters seek out their niche places late at night as it is forbidden to skate in public spaces throughout town. Yet, these niche places are coopted by commercial enterprises such as Adidas in stylish documentaries (Rozu///Adidas Skateboarding in Japan, accessed on 20 February 2018 on youtube). This shows the double-edged ambiguity of hip hop as a platform for varying target groups including both subaltern and dominant.

This study aims to ethnographically illustrate how members of the Generation Resignation make sense of their worlds by engaging in hip hop. By doing so, it portrays the generational change that is presently occurring in Japanese society. Characterized by economic stagnation, increasing pressure on the labor market and a sense of resignation, anomie, introversion and risk aversion, contemporary hip hop practitioners differ from previous generations of hip hoppers: reluctant to criticize others, they avoid taking open sides on any issue, seem uninterested in engaging in close relations with other practitioners and take rigid hierarchical relations in the scene as a given. Numerous practitioners indicated that in comparison to a few years ago, relations have become more casual and more relaxed between senior and junior practitioners. A veteran in his mid-40s pointed out that in his impression, Club Ghetto has not changed too much.

However, a thirty-year old DJ and scratcher humorously observed, "Back then, Club Ghetto felt so much darker than now. Everyone would down one drink after the next whereas I would be sipping my cassis orange." (interview on 9 December 2015) That being said, I heard numerous stories of younger practitioners being forced to imbibe alcohol although they were not comfortable drinking; I also witnessed a younger hip hopper being forced to consume large amounts of alcohol in Club Ghetto in downtown Sapporo where I conducted a large part of my fieldwork. In other words, genuflection based on seniority seemed deeply ingrained in practitioners' narratives and actions and echoes Condry's point that despite the transnational heritage of hip hop, practitioners "also live in a day-to-day world that is distinctly Japanese" (2001: 374).

Numerous veteran practitioners observed that with the increasing popularity of hip hop dance beyond the scene, hip hop has been subjected to commercialization that 
has resulted in a cooptation of mainstream elements and eventually given rise to a hybridization of underground and mainstream scenes. Yet, coverage that focusses on hip hop as a distinctly subcultural phenomenon still dominate in Japanese media (e.g. an interview with rapper $\mathrm{KOHH}$ https:/www.numero.com/en/music/kohh-japanese-hiphop-fashion, a documentary on "Riverside Mobb" in north Tokyo https://bitchslapmag.com/blog/2014/03/04/kohh-interviewed-by-vice-japan/ or a vice documentary on the contemporary crew 'Bad Hop' https://www.vice.com/jp/article/ywk84x/made-in-kawasaki-bad-hop [all accessed on 2 December 2018]). Whereas the interview with rapper KOHH indicates that some rappers manage to transcend hip hop, Kohh also argues that in Japan, hip hop has not been accepted by a wider public as a cultural phenomenon and is listened to by a limited audience (2017 documentary on 'Riverside Mobb').

In the next section the role of work will be examined in members of Generation Resignation and how work relates to their engagement with hip hop. Section Three will discuss methodological issues of positionality as a fieldworker and challenges of building rapport with interlocutors. Section Four dissects the ambiguity of hip hop as a musical genre by discussing the polyvocality of hip hop practitioners and in media. Section Five will illustrate social change that is evident in hip hop in Hokkaido by examining how agency and subjugation concur in the narratives of practitioners. The final section will bring together the common threads that emerged from empirical data presented, summarizing what insights these narratives and trajectories provide about societal changes in contemporary Japan.

\section{Work and hip hop}

"My personality when I do hip hop and when I work during the day? Totally different. I work at the city hall on weekdays and am a shadow warrior like a ninja at night and on weekends." (M, 26)

"I have been pretending to be a corporate slave [shachiku], but in fact nothing could be more distant from the truth." $(\mathrm{M}, 30)$

In line with media representations described above, readers may be tempted to associate hip hop practitioners with low educational backgrounds, working class origin 
and manual labor. The reality is quite different in Hokkaido: Among my twenty-five informants, one third had university degrees and worked as white-collar employees, a number of them as regular workers with lifelong contracts or as self-employed professionals. Some work in call centers, coffee shops, bars, others as carpenters, car mechanics, shop owners, craftsmen, as graphic designers or in visual documentation. There were only two interviewees who came from single-mother-households who grew up in financially and emotionally difficult circumstances. Most interviewees have spent all of their lives in Japan and have little interest in going abroad, also because they do not feel confident about their English skills. Nevertheless, a thirty-year old scratcher pointed out that sometimes English words such as "What's up?" would slip into his Japanese vocabulary in daily life as a result of his career as a turntablist (interview on 9 December 2015).

Altogether, having attended over sixty live performances in the scene, I found the mostly male pale, thin and tacit practitioners, sporting identical black hoodies and sneakers, a rather challenging group of interlocutors for reasons that will be discussed in the following section.

More senior representatives of hip hop in their forties or fifties have attempted a clean break from mainstream society, creating their own alternative lives in the process. For example, one member of the cult-like hip-hop formation Mic Jack Production opened his own shop selling hip hop fashion in downtown Sapporo, while doing occasional gigs as a rapper, mostly in mainstream gig locations. He was described by one of his staff as 'overground' compared to other members of Mic Jack Production (interview on 18 June 2015). Other practitioners opt for opening their own club, such as charismatic MC Big Joe. A hip hopper in his late twenties has opened a recording studio that offers technical support to artists aspiring to producing their albums and tracks.

However, in general younger practitioners in their twenties or thirties tend to pursue conventional careers, retreating into double identities. There were only three interviewees who clearly remarked that for them, becoming a corporate employee was never a choice. Another 30-year-old scratcher observes that he finds wearing supersized (dabo dabo) clothes comfortable and could not imagine putting on a necktie (interview on 9 December 
2015). One of my key informants has renounced work altogether after his career as a DJ in Club Ghetto ended. In his mid-40s, he does not engage in any kind of work (even temporary) but spends his days skateboarding, surfing the internet and occasionally attending hip hop events in Club Ghetto. He lives with and on the pension of his parents who seem to have given up trying to persuade him to resume work. Driving the meticulously maintained Toyota of his parents with lace-decorated seats may not fit conventional images of hip hoppers, yet this is the reality: Renouncing any form of labour and materialism, yet being concerned about which brand of sneakers to wear (Adidas, not NIKE); complaining about his material reliance on his parents, yet resigning that nothing can be done to change it. Drawing on the repertoire of protest parlance of hip hop, yet remaining a social introvert in daily life.

This implies a sense of resignation that it is impossible to make a livelihood through hip hop in north Japan and hence, the conclusion that individuals need to blend into a conventional working environment during weekdays. "Without money it is impossible to make music. If I had the chance to earn my living through music, I would go for it, but here in Sapporo, I only know one guy who can actually earn a living from his music" (interview on 10 June 2015). This sense of resignation is evident not only in the hip hop scene, but also in other music scenes and in the contemporary art scene in Sapporo. The fact is that the average annual income is conspicuously lower than in Tokyo: 3.710.000 JPY in Hokkaido versus 4.520.000 JPY in the Japanese capital (These figures are from 2017, doda.jp, accessed on 3 February 2018). Interviewees usually refer to Tokyo in negative terms of commercialism, but also express their jealousy about the opportunities that come with material affluence as chances are higher that performers can make a living from music (interview on 14 February 2014).

Yet, the majority of interviewees do not seem to perceive their jobs (if they work) as a constraint, indicating that they like to practice hip hop in their time off work rather than devoting their entire time to it.

Regardless of the diversity of narratives, resistance to societal beliefs featured in some way or another, be it Japanese traditional values of persistence at work, emphasis on seniority, the assumed path of corporate employment, the lack of credibility of persons embodying authority and the like. One of the members of Mic Jack Production, a rapper 
in his forties who usually wears casual clothes, conceded: "In fact, it was my explicit wish to be in an environment where I don't have to wear a necktie. My family did not understand me at all." (interview on 25 June 2015). Corporate employment embodied hegemonic masculinity in Japan until recently and continues to stand for (performances of) mainstream masculinity (Dasgupta 2000). Not only did this interlocutor make a conscious decision for self-employment, but he also renounced starting a family or partnership.

However, younger interviewees, e.g. a DJ and beat maker in his late 20s mentioned his general pessimism about the world given the widening gap of poor and rich and conspiracy-like theories about affluent networks controlling power, explaining that for him, the club constituted 'his realm - something that he would not give away to anyone', which also implies a mental resistance of sorts (interview on 15 May 2015). Similarly, a producer, beat maker and DJ in his late 30s who is one of the key persons of the hip hop scene in Sapporo confessed that for him engaging with hip hop constitutes a means of escaping from the stresses of his everyday life as a graphic designer (interview on 27 May 2015). Narratives of hip hop practitioners indicate that few hold aspirations to take on traditional roles as daikoku-bashira (literally: holding up the roof, meaning male breadwinners, see Gill 2003). Numerous of my interlocutors seem to opt out of starting relationships or families altogether, with hip hop constituting an arena for them to withdraw to. Nevertheless, some narratives confirm the prevalent view that irregular workers represent a 'failed' masculinity (Hidaka 2010). Interviews with hip hop practitioners also reveal that male freeters often perceive themselves as inferior to male peers with lifelong contracts.

\section{Entering the field: Silence, non-reflection and age}

Figure 1: Entrance of Club Ghetto (image taken by author, 13 June 2015)

On an autumn weekday in 2013, I ventured into Club Ghetto, pushing open the heavy iron door. I could not resist my curiosity to see what it was like although I did not have a personal interest in hip hop music prior to this research project. Stale smoke-filled air mixed with a faint hint of sweet incense lingered in the dark corridor. Narrow steps 
lead down past an empty counter to a bar with two guests and the gaunt bartender sporting a black baseball hat. They all looked at me with a mixture of surprise and sense of uncertainty, indicating that only acquaintances and friends frequented the place. Yet, five years later, in January 2018, I passed the same club when a group of mainstream looking youth were standing in front of the heavy door. It was a private party not open to the public. Does this constitute a 'sell-out' of Sapporo's leading underground scene site?

I claim the contrary: In fact, practitioners who have been on the scene for some twenty years point out that representatives of today's Hokkaido hip hop such as Boss of the formation Tha Blue Herb, who has gained cross-national and international recognition, originally came from the rock scene and only entered the Ghetto scene recently. One of the veterans on the Sapporo hip hop scene, states that "the major contribution of Boss was to musically open up the local hip hop scene" (interview on 10 June 2015). Similarly, numerous representatives of underground hip hop in Sapporo who I interviewed originated from the house or dance scene. Hence, ingrained hybridity with regard to the cultural genre seems more the norm than the exception, as will be further elaborated on in Section 4.

In retrospect, entering the field contained several challenges: I initially assumed that doing ethnographic research as a female scholar in a field dominated by male practitioners would be disadvantageous. Whereas it was difficult to venture into sites of male bonding and networking (although this was more of a mental hurdle than a physical issue), there were advantages about being female. Some male informants opened up about their daily routines and trajectories much more than expected and shared their intimate thoughts on the scene and its players, especially when meeting them for interviews outside of the genba (the field, Condry 2006). Participant observation at various sites including clubs in southern Hokkaido (Sapporo, Tomakomai, Otaru), skate parks where hip hop events took place and public spaces where skaters associated with the hip hop scene gathered suggest that females do attend these events mostly as guests or dancers, yet few are accepted as equal and full members of the scene.

Misogynist expressions in raps and remarks to the audience were prevalent; unsurprisingly, partners and wives of practitioners only rarely attended events unless they were active performers themselves. These findings echo extant research into the role of 
female hip hoppers in other contexts: "Young women's efforts to make a place for themselves in hip hop - and to reap the same benefits of agency, articulation and acceptance that their male counterparts enjoy - are doubly constrained by the same traditional norms that make rappers seek to circumvent via hip hop practice and by the very masculine overtones of (Senegalese) hip hop itself. (Appert 2016: 253). In a similar vein, Beer writes about 'the gender divide' in hip-hop (2014), with 'voices emerging from hip-hop tend[ing] to be overwhelmingly male.'

Second, a greater challenge was the fact that I work as faculty at a national university. Although I sought to keep my day job low profile when hanging out (although I evidently explained my research project), practitioners soon started calling me "Sensei" (professor in Japanese). I felt that the conduct of qualitative research was complicated by the sense of distance and awe mixed with derision that many practitioners expressed towards academics. Third, and this is related to the previous point, my age (being in my early forties at the start of this project) was a larger element of interest to practitioners than anticipated. Generally, practitioners socialized rigidly in age groups, hanging out with those of similar age. Everyone over 40 was classified as 'old', too old for hip hop was the implication. Even the owner of Club Ghetto, a male in his mid-40s, conceded that he hardly attended his own club since he felt it is better "to leave it to the kids." (interview on 18 March 2015) Mullaney has argued that "age can work for and against the performance of authenticity" (2012). In a similar vein, my fieldwork has revealed that more senior individuals are met with a mix of respect, awe and derision. Senior practitioners hence often take themselves back, linger backstage and give occasional advice, but generally are self-conscious of being judged negatively by younger peers. On the one hand, they complain about younger practitioners treating veterans with insufficient respect despite their lack of experience and technique, but more senior practitioners also seem to accept this ingrained value system revolving around age rather than performance.

One of my key informants was a former practitioner in his mid-forties from Sapporo who had organized club events, worked as a long-term DJ in Club Ghetto and continued to attend some events there. Kei's accounts of the scene were highly insightful, but also revealed the small size of the scene and the complex and constraining social 
relations between practitioners. This 'insider knowledge' (Bennett 2002: 464) greatly advanced my understanding of the scene itself; yet my frequent outings with this key practitioner doubtlessly placed me in a certain part and age group of the scene - a point previously made by Matsue with regard to her ethnomusicological study of the Tokyo hardcore scene (Matsue 2009: 16). Due to my long-term association with Kei I managed to access the club and various events for the reduced fee for 'kankeisha' (people related to the scene), attending events that were only announced within the scene. However, this 'insider' status (if preliminary) combined with my being a foreigner, female and very different in habitus from other women in the scene resulted in my uneasy status during fieldwork.

Fourth, some key practitioners declined interviews so that I resorted to extensive participant observation rather than pestering verbally disinclined hip hoppers with questions. Interviews were conducted in Club Ghetto, Club Morrowzone, cafes close to Club Ghetto, during drives to and from events or in my flat. Fieldwork consisted of attending club events in Sapporo, Tomakomai and Otaru, visiting record shops and fashion shops associated with the hip hop scene, performing as a DJ in Club Ghetto, hanging out in the closely related skateboarding scene and attending beat making events and scratch battles. Last but not least, SNS including Facebook, Twitter and Instagram also provided valuable insights into the thoughts and values of introvert practitioners. All in all, pursuing fieldwork "not of but with" practitioners as suggested by Ingold (2008, 2014) was harder than expected not due primarily to my gender, but my day job and age. Green contends that "those conducting ethnography into hip hop creativity may respond best by learning to be comfortable feeling awkward" (2017: 57) as fieldwork often brings out the diverging values and worlds of fieldworker and interviewees.

In hindsight, age and gender may have been alienating elements. However, the greatest challenge for me was to overcome the hurdle as someone who had not been emotionally invested in hip hop prior to my research, as someone who came from a world where everything needed to be permanently questioned and accounted for verbally. This verbal fixation regularly met with persistent silence in the hip hop scene - something that felt like failure especially in the early stages of fieldwork. Practitioners often replied that they had never thought about my questions. Others just shrugged their shoulders, saying 
that they prefer to think with their bodies. Without doubt, awkwardness was not limited to myself: I remember the unease and discomfort in one practitioner when I asked him about his baseball clothes at an outdoor hip hop event. The implication was that such things were not talked about or questioned, just done. Practitioners rarely seemed to question their actions - non-reflection seemed pervasive.

\section{Polyvocality and hybridity of hip hop as a genre}

"It's my belief

That history is a wheel

'Inconsistency is my very essence' says the wheel

Rise up on my spokes if you like

But don't complain when you're cast back down into the depths

Good times pass away but then so do the bad

Mutability is our tragedy but it's also our hope.

The worst of time, like the best, are always passing away."

(Boethius [Anicius Malius Severinus 480-524 AD] cited in Rebel Musical DJ Kei, The Anthem, 2013)

Although constructions of hip hop as a clearly defined culture of resistance seem ubiquitous, the impressive diversity of musical influences and genres appropriated by hip hop practitioners in Hokkaido suggest that Boethius' statement about mutability as the very essence perhaps being the key feature. The fact that Rebel Musical also known as DJ Kei, a Sapporo local in his late 30s, referred to a prehistorian Roman, in one of his tracks says it all: Hokkaido hip hop crosses national as well as time borders permanently and without apparent effort. Jazz, soul, disco, baroque, folk elements all are referred to in progressive ways and molded into something that for lack of words is categorized as hip hop. In a similar vein, Morris defines Japanese hip hop as "a moment of aesthetic risk, in which an art form is pushed beyond its predicated limits in a new direction" (2010:5).

Figure 2: A flyer promoting the Nola Block Party, an outdoor hip hop event in Otaru

Hokkaido practitioners may not seem likely to mobilize change directly; yet, they refer to disillusionment and change in indirect ways (as in the reference to Boethius by 
Rebel Musical). Lamotte observed that "Resistance is never simple and singular. Nor is it exempt from ambiguity. [...] Hip-hop is simultaneously an identity built in a social and spatially hidden position, and a practice loudly enunciating its existence in the face of the city." (Lamotte 2014: 692) Needless to say, Lamotte's understanding of complex resistance is heavily informed by Ortner's notion of multifaceted resistance (1995), Bhabha's postcolonial concept of ambivalence (1985) and Foucault's notion of circulating power (1980).

I similarly claim that in the case of hip hop in Hokkaido, accommodation and resistance coexist in complex ways. Practitioners are deeply divided about mainstream values; yet, at the same time, practitioners coopt elements of mainstream lifestyles as members of mainstream society, even if they probably do not like to perceive themselves as such. Just as the long-term hip hop aficionado who works as a full-time employee of the municipal hall with a lifelong working contract, many practitioners have settled for the mainstream in their respective ways; yet they choose to opt into hip-hop lifestyles at given times. Pieterse argues that hip-hop music "offers an alternative sense of place, a means of interpreting the world." What if some practitioners referred to this way of being just for limited periods, opting out and coming back to opt in again when it suits them?

My findings indicate that such 'inconsistency' is quite common in practitioners and can be interpreted as a way of strategic wriggling in order to eventually achieve mobilization in subtle ways in a society that continues to be consumption-driven despite increasing awareness of the limits of material growth. In many cases, practitioners' "acts of resistance or subversion require the façade of compliance while effectively undermining the structure of power from below" (Kurotani 2005: 19).

Such 'inconsistencies' in individual narratives aside, we need to face the issue of hip hop as a genre being highly controversial and 'highly malleable' (Drury 2017) or as Adedeji has put it, "a combination of styles which thrives on hybridity" (2013: 1). A statement by one of the veterans on the Sapporo hip hop scene confirms this: "For me it's no longer exclusively about hip hop. For me it's about scratching and transcending musical genres. I like house music - I am not concerned about the fact that it is associated with gay culture. Through hip hop I encountered various musical genres including dance 
music, black music, techno and house music" (interview on 10 June 2015). At the same time, however, this statement highlights the conspicuous lack of diversity and tolerance in Hokkaido. In one of my extensive conversations with the bartender of Club Ghetto, he remarked with lingering derision that he does not know anything about the gay scene nor has he any relations with them. This episode echoes Haenfler's claim that "some subculturists' beliefs and behaviors actually reinforce dominant ideologies and relationships" (Haenfler 2014: 59).

Watkins also contends that "there has never been a consensus within hip hop about its purpose, identity, or destiny. In fact, the most robust debates about hip hop have always taken place within the movement. Hip hop has and continues to be its most potent critic and courageous champion." (Watkins 2005: 5). My fieldwork and interviews over the years indicate that hip hop practitioners understanding of hip hop values tend to be diverse, with many implying that they perceive themselves as individual actors rather than part of a coherent scene with its clearly defined set of values. After all, Watkins has observed that "hip hop has always been a community of different voices, experiences, and perspectives." (2005: 253). Best similarly argues that hip-hop in Newfoundland "takes many forms and is not a unified or homogeneous scene" (2007). With regard to Hokkaido, representative groups such as Mic Jack, Tha Blue Herb and individual beat makers such as Rebel Musical, DJ Hisaya or Mister Bee to name but a few all come from very diverse musical backgrounds, with little common ground. For this reason, there seems to be little consciousness and exchange about shaping the scene in Sapporo and Hokkaido as an artistic community, as 072, a female rapper from East Hokkaido observes (interview on 18 June 2015). Many artists leave Hokkaido for personal or other reasons, including Shuren the Fire, DJ Ken (both members of Mic Jack Production) or DJ Honda, either abandoning their musical careers in the process (the former) or continuing as artists (the latter two).

Bennett has elaborated on the importance of rap and hip hop as viable local resources (Bennett 1999:78). Evidently, any hip hop scene and its appropriations reflect the characteristics of a given locale, its histories, mentalities, economies, politics. In this sense, hip hop in Hokkaido reflects its specific history as a colony, frontier and marginalized territory (Guarne and Hansen 2017). Several times scene members referred 
to peers who have 'dissolved into thin air', which apart from the historic aspect of escapee culture associated with Hokkaido prisoner heritage emphasizes the inherent lack of communication and fluidity of social ties. Furthermore, in contrast to egalitarian ideals of this musical genre, hip hop in Hokkaido often goes hand in hand with hierarchical social relations between younger and elder practitioners that resemble social relations between corporate employees. Yet, in contrast to Condry's suggestion of regional specificities of certain hip hop scenes in Japan as indicated in his reference to 'Sapporo-style' rappers (2006: 162), my findings indicate a deeply divided scene, with individual stakeholders engaging in hip hop in ways that make sense to them personally. According to a wide range of interviewees, the genba - i.e. "the actual sites where the gamut of participants in the scene perform, socialize and network" (literally field site, Condry 2006: 207) are clearly being ascribed less importance than ten years ago as performers in their twenties tend to go to clubs less than their senior peers.

Despite my doubts about a 'locally homogenous scene', I contest that inclinations such as shyness, introversion, lack of communication between scene members, stagnation and lack of confidence in musical skills specifically with regard to Tokyo is nothing but a reflection of the difficult relationship Hokkaido has had with central Japan. Practitioners seem torn between jealousy and dismissal towards Tokyo, the embodiment of the 'big money (and sellout)'. Yet, performers who have gained national and international recognition needed to build a reputation beyond Hokkaido. The chosen few practitioners in Hokkaido who manage to make a living out of hip hop, were often eyed with derision by their peers, being depicted as sellouts who had given up their artistic interest in favor of commercialism. Facades of individualist underdog mentality were carefully crafted by some, with an ensuing lack of exchange with peers. As one practitioner put it: "I am not really interested in social ties, so I meet up with loads of peers but avoid being close friends with anyone [hiroku asaku tsukiatteiru]" (interview on 22 January 2016).

\section{Hip hop practitioners between accommodation and subordination}

It may strike some as an irony that one of the key beat makers in Sapporo asked me after our initial interview what people I am friends with (interview on 22 January 2016). This question confirms the underlying paradox of turf consciousness, petty politics and social alienation threatening artistic creativity in a medium-sized local town in Japan. 
Similarly, Takashi, who has just turned twenty and is a passionate DJ originally from Western Japan, shared his disappointment with ingrained seniority and predominance of turf over policy and values in Sapporo with me. Wearing X-sized clothes in 90s old-school hip hop style, he is described as "the last bboy" by a veteran of the scene (interview on 10 June 2015). Takashi struggled blending into school in an unfamiliar city and having a single mother suffering from bouts of severe depression did not facilitate his integration. For him, hip hop constituted an alternative space; after all, he had contemplated suicide (interview on 29 November 2015). He was all the more disappointed when he found out that his expectation that anyone with outstanding turntable skills would be rewarded turned out false: he encountered mobbing, pressure and unsurprisingly, flattering strategies by those relatively unexperienced keen on making career moves despite lacking skills.

Takashi observed that aspirational egalitarianism that was supposed to be one of the key reference points in hip hop was often replaced with the practical reproduction of mainstream values of seniority regardless of one's performance. Furthermore, he criticized his peers for discarding their policies for some short-term advantage, implying that practitioners lack principles and beliefs. Disappointed with the way things worked in the local hip hop scene, he decided to pursue his passion for hip hop as a leisure since he did not wish to sacrifice his artistic freedom. He describes hip hop as "his stage" as he did not have a place to be (ibasho) neither in his family due to the complicated domestic circumstances he grew up in nor in school as he found it hard to make friends after his move to Hokkaido (interview on 29 November 2015). He says that not a day goes by without him listening to hip hop, thinking about tracks he likes or making beats himself in his leisure time. "I have really been saved by hip hop" he emphatically states with a happy smile. He adds, however, that he cannot relate to hip hop that focusses on drugs, women and violence since these themes do not feature in his life - a point that was also reiterated by other practitioners. Rather, he likes hip hop that deals with people at the margins who have coped with their situation and managed to gain control of their lives as he personally also encountered hard times as a teenager.

Talking to Takashi makes the outstanding importance of hip hop for him evident: rather than a mere leisure pursuit, for him it is clearly a source of inspiration, relaxation 
and well-being. He says that when he spends time in Club Ghetto, he feels that he is closest to 'his real self', especially compared to his mode when working, as in the club he can be himself without consideration for others and all the obligations of being a shakaijin (literally 'a person in society' denoting a responsible member of society, usually male, who works in full-time corporate employment, Ho 2015: 48). Both Takashi and others describe Club Ghetto as their 'home' and 'living room'; a veteran of the hip hop scene who used to be the boss of the club for some ten years adds that this club "has definitely shaped him into the person he is today." (interview on 10 June 2015). According to him, Club Ghetto has not changed at all; but the line between overground and underground used to be more distinct before, with no exchange occurring between the scenes.

Hiro, a 25-year-old scratcher from Sapporo works as a carpenter in his day job. Quiet, broody and introvert, he asks me about a German rapper, and it is obvious that he has engaged in in-depth research on overseas underground hip hop. For him, the fact that he holds a day job is the ideal complement to his passion: "Even if I work in an unrelated job, I engage in hip hop. And because I have this interest in music, I can do my job. Through my engagement with music, my work motivation also increases" (interview on 25 June 2015). Rather than being interested in engaging with the hip hop scene, Hiro holds a genuine interest in old-school (i.e. 90s) hip hop. Since in his opinion, hip hop has a 'bad' image generally, he avoids talking about hip hop with his friends from his school days since he does not wish to be labeled in a negative way by mentioning his passion. Quite in contrast to Hiro, Yasu, an outgoing turntablist from Sapporo who has just turned thirty started out as a hip hop dancer in secondary school. Having grown up in a strict family with severe curfews, he remembers that clubs were out of his reach back then. Having done a broad range of jobs after studying at a vocational college for car mechanics after graduating from high school, he works in a call center now and concedes that he thinks about hip hop when he has free time at work. "My life would be meaningless if I could not go on scratching anymore for some reason." (interview on 9 December 2015) For him, the eventual aim is to carve out a career in music by gaining a reputation at the national and international level. He started out as a club DJ but is now mostly interested in pursuing a career as a battle DJ who participates in competitive performances. 
He is planning to work hard to improve his scratching skills for some more two years as he thinks that he will be able to make an entry into the national DJ battle by then. Asked about his motivations to be a DJ, he says that he likes to stand out (medachitai), be popular with girls and he enjoys playing in front of a crowd since he is the social type. "I am not doing this for some specific reason other than the fact that I really enjoy doing this." I ask him whether there are any political motives in his music. "Not really. I am not interested in politics. Japan is finished, after all. It's not at a level where any activities on my part would make any difference." (interview on 9 December 2015).

Pei, a beat maker in his late twenties, has a university degree from Tokyo and works as a full-time company employee during the day. For him, the club is his place to be (ibasho) that he would not want to give away to his work peers. At work, he is the committed professional. But in his own words, he is not his 'self' as he is always careful to appear as the dedicated employee. The stress that he experiences during work needs to be released and this is where hip hop comes in. For him, hip hop is the forum that allows him to express himself at a personal level (interview on 15 May 2015).

\section{Hokkaido hip hop as arena of societal engagement}

The empirical data obtained throughout my fieldwork indicate the strong local appropriations of Hokkaido hip hop reflecting the locally ingrained history, just like in other places throughout the world. The findings above echo Mintz's and Price's idea that "hiphop is eminently a product of the socio-historic circumstances of its birthplace and emergence not of some primordial unchanging African essence (1992). Although hip hop originally emerged as a resistance practice (Lamotte 2014: 687), both overground (i.e. mainstream) and underground values are salient in contemporary Hokkaido appropriations.

Whereas evidently individuals have different priorities and mindsets, the narratives introduced above suggest an increasing influence of mainstream beliefs and values in hip hop practitioners. This is why hip hop needs to be approached in a more nuanced manner as voices of practitioners clearly illustrate that as a musical genre, lifestyle and leisure activity, it transcends clear-cut categories in various ways. Furthermore, as Lamotte has poignantly argued, "Resistance is never simple and singular. Nor is it exempt from 
ambiguity. [...] Hip-hop is simultaneously an identity built in a social and spatially hidden position, and a practice loudly enunciating its existence in the face of the city." (Lamotte 2014: 692)

In line with this understanding of ambiguous resistance that is open to contextual change and subtle positioning, hip hop practitioners in Hokkaido simultaneously coopt practices of accommodation and resistance. Many hold day jobs that are unrelated to their musical interest; the majority of them prefer to pursue hip hop as a temporally defined leisure activity that they intend to pursue permanently, but do not seem to view as a holistic lifestyle. Whereas previously, social relations between practitioners were stronger as scene members had a distinct sense of identity as members of the underground, nowadays individual narratives indicate an introspective mood: Practitioners tend to keep to themselves, with their musical interest taking priority, with many conceding that they only go to clubs when they are invited to perform.

Openly identifying with given values or policies seems to be regarded as obsolete by many and hence little explicit reference is made to resistance, criticism or activist pleads for social change of any sorts. Rather than serving as a "creative and recreational outlet for marginal youths" (Watkins 2005: 149), hip hop in Hokkaido seems to function as a highly malleable arena of societal engagement for youth that coopt, but simultaneously question mainstream values. It is important to note that this does not imply that hip hop in northern Japan is entirely devoid of resistance or that local youth have totally resigned. Futatsugi concedes that underground rap music in Japan cannot be compared with the political impact of rap in the United States, but nevertheless contends that it contributes to refining anarchist sensitivity through its underground activities (2013: 34).

As Guarne and Hansen note, there is a broad diversity of forms of escape that range 'from subtle dissent, 'agreeing not to agree' or 'letting things be,' to trenchant and pugnacious opposition in the face of the social and political assumption of an ethnically and culturally homogeneous Japan." (Guarne and Hansen 2018: 13). Ambiguous resistance or 'everyday resistance' in the meaning of informal and non-organized resistance as conceived by James Scott (1985) is just different from explicit forms of activism often seen in Western countries and can been seen as a form of long-term and 
small-scale resistance with its own implications. And after all, Perry has observed with regard to hip hop in the United States, that it involves "the use of commodity to dislocate commodity." (2004: 201)

Drawing on this tradition of assemblage inherent in hip hop, individual narratives by hip hop practitioners in Hokkaido suggest the prominent lingering influence of social constraints. I have discussed Yasu, who chuckles that casual English terms slip into his Japanese formal polite language at the workplace; yet at the same time he talks with great respect about his strict father who forbade him to go out at night as a teenager. Clearly, subjection to and questioning of given hegemonic regimes all feature in these narratives and the complex entanglement with power is evident. Takashi's main passion is hip hop, yet he has chosen to work in an unrelated job that is highly focused on service, seniority and sacrifice. Hiro works as a carpenter in a milieu that is characterized by traditional attire, strict seniority and rigid formality; yet in his leisure time, he engages in a musical genre that emerged from radically different social contexts. As diverse as these individual actors may be, they all engage in various forms of 'silent dissent' (Guarne and Hansen 2018) that "is always an ongoing and unresolved project that never totally succeeds in leaving behind one's personal past, social constraints and cultural imaginings. It is always a failed attempt to flee that has more to do with binding than with a complete release." (Guarne and Hansen 2018: 14).

These subtle forms of resistance concurring with lingering references to mainstream values and social constraints and markers are empirical proof of "divided selves, divided situations, divided practices" (Morris 2010: 42). Face-on derision of postwar values coexists with subtle indication of resistance; senior hip hop practitioners plead for musical diversity by referring to other musical genres, yet they often imply highly prejudiced views. It is exactly these 'inconsistencies', paradoxes and breaks between underground and overground that make hip hop so relevant to its practitioners in contemporary Japan. The narratives of practitioners introduced above reveal that hip hop is a permanently evolving arena of both social engagement and withdrawal that airs the disjuncture, disconnect and disillusionment of members of the Generation Resignation in contemporary post-growth Japan. 


\section{Acknowledgments}

The author cordially thanks numerous representatives of the hip hop scene in Hokkaido for their time and patience; without their generous help and time this study would not have been possible. This research received no specific grant from any funding agency in the public, commercial, or not-for-profit sectors.

\section{References}

Adedeji W (2013) African Popular Culture and the Path of Consciousness: Hip Hop and the Culture of Resistance in Nigeria. Postcolonial Text 8 (3 \& 4): 1-18.

Appert C M (2016) Locating hip hop origins: Popular music and tradition in Senegal. Africa 86 (2): 237-262.

Beer, David (2014) Hip-Hop as Urban and Regional Research: Encountering an Insider's Ethnography of City Life. International Journal of Urban and Regional Research. Onlinelibrary.wiley.com (accessed 6 December 2018).

Bennett A (1999) Hip hop am Main: the localization of rap music and hip hop culture. Media, Culture \& Society 21: 77-91.

Bennett A (1999) Rappin' on the Tyne: white hip hop culture in Northeast England - an ethnographic study. The Sociological Review 47(1):1-24.

Bennett A(2002) Researching youth culture and popular music: a methodological critique. British Journal of Sociology 53(3) (September): 451-66.

Best, K (2007) Hip-hop on the East Side: A Multi-sited Ethnography of Breakdancing and Rap Music from St. John's and Grand Falls, Newfoundland. Newfoundland and Labrador Studies, Vol. 22, No.1. journals.lib.unb.ca (accessed on 6 December 2018).

Bhabha H (1985) Signs taken for wonders: questions of ambivalence and authority under a tree outside Delhi. Critical Inquiry 12.1: 144-65.

Condry I (2001) Japanese Hip-Hop and the Globalization of Popular Culture. In: George Gmelch and Walter Zenner (eds.) Urban Life: Readings in the Anthropology of the City. Prospect Heights, IL: Waveland Press: 357-387.

Condry I (2004) B-Boys and B-Girls: Rap Fandom and Consumer Culture in Japan. In: Kelly, W. (ed.) Fanning the flames: fans and consumer culture in contemporary Japan. Albany, NY: State University of New York: 17-40.

Condry I (2006) Hip-Hop Japan Rap and the Paths of Cultural Globalization. Durham and London: Duke University Press. 
Connell, R and Messerschmidt, J (2005) Hegemonic Masculinity: Rethinking the Concept. Gender and Society 19(6): 829-59.

Cornyetz N (1994) Fetishized Blackness: Hip Hop and Racial Desire in Contemporary Japan. Social Text 41 (Winter 1994), Duke University Press: 113-139.

Dasgupta, R (2000) Performing masculinities? The 'Salaryman' at Work and Play, Japanese Studies 20(2): 189-200.

Drury M (2017) Counterorienting the war on terror: Arab hip hop and diasporic resistance. Journal of Popular Music Studies 29(2): 1-11.

Fischer D (2013) Blackness, Race, and Language Politics in Japanese Hiphop. Transforming Anthropology 21(2): 135-52.

Foucault M (1978) The History of Sexuality: An Introduction. New York: Random House. Futatsugi, S (2013) Shikujiru na yo, Rudi [Rudie can't fail]. Tokyo: P-Vine Books.

Gardner, A and Hoffman, D M (2006) Dispatches from the field: Neophyte ethnographers in a changing world. Long Grove, Illinois: Waveland Press.

Gill, T (2003) When Pillars Evaporate: Structuring Masculinity on the Japanese Margins. In Men and Masculinities in Contemporary Japan. James Roberson and Nobue Suzuki (eds.). London: RoutledgeCurzon: 144-161.

Green, A (2017) The Ethnography of Hip Hop Nostalgia: Indigeneity, Intimacy and 'Roots' in Mexico. Suomen Antropologi 42, Issue 2, Summer 2017: 43-59.

Guarne B and P Hansen (eds.) (2018) Escaping Japan: Reflections on Estrangement and Exile in the Twentieth-First Century. Japan Anthropology Workshop Series, London and New York: Routledge.

Haenfler, R (2014) Subcultures: the basics. Abingdon, Oxon and New York: Routledge. Han, Byung-Chul (2019) Vom Verschwinden der Rituale: Eine Topologie der Gegenwart [The Disappearance of Rituals: A Topology of the Present]. Berlin: Ullstein.

Harkness G (2012) True School: Situational Authenticity in Chicago's Hip Hop Underground. Cultural Sociology 6(3): 283-98.

Hidaka, T (2010) Salaryman Masculinity: The Continuity and Change in Hegemonic Masculinity in Japan (Leiden: Brill Academic Publishing).

Ho, S-L (2015) 'License to drink': White-collar female workers and Japan's urban night space. Ethnography 6(1): 25-50.

Ingold T (2008) Anthropology is not Ethnography. In: Radcliffe-Brown Lecture in Social Anthropology 2007, Proceedings of the British Academy 154, 69-92. 
Ingold T (2014) That's enough about ethnography. HAU: Journal of Ethnographic Theory 4: 383-395.

Johansson A and Vinthagen S (2016) Dimensions of Everyday Resistance: An Analytical Framework. Critical Sociology 42(3): 417-435.

Kelly W (2004) Introduction: Locating the Fans. In Kelly W (ed.) Fanning the flames: fans and consumer culture in contemporary Japan, Albany, NY: State University of New York: 1-15.

Kurotani S (2005) Home Away from Home: Japanese Corporate Wives in the United States. Durham, NC: Duke University Press.

Lamotte M (2014) Rebels without a Pause: Hip-hop and Resistance in the City. International Journal of Urban and Regional Research 38.2. March: 686-94.

Manabe N (2013) Representing Japan: 'national' style among Japanese hip-hop DJs. Popular Music 32, Special Issue 01, January: 35-50.

Manabe N (2015) Japanese hip-hop: alternative stories. In Justin A. Williams (ed.) The Cambridge companion to hip-hop. Cambridge, UK: Cambridge University Press: 243255.

Matsue J (2009) Making music in Japan's underground: the Tokyo hardcore scene. New York and Abingdon: Routledge.

Maxwell I (1997) Phat Beats, Dope Rhymes: Hip Hop Down Under Comin' Upper. University of Sydney, Ph.D. Thesis, Centre for Performance Studies, July 1997, 432 pages.

Maxwell I (2009) True to the music: authenticity, articulation and authorship in Sydney hip hop culture. Social Semiotics 4(1-2): 117-137.

Mintz S and Price, R (1992) The Birth of African American Culture. Boston, Mass.: Beacon Press.

Mitchell S. (2014) Hegemonic Resistance in Hip-Hop Music: A Gramscian Rhetorical Criticism of Tupac Shakur. Master Thesis, Illinois State University. 159 pages.

Morgan, M (2009) The Real Hiphop: Battling for Knowledge, Power, and Respect in the LA Underground. Duke University Press.

Morris D (2010) Minzoku madness: hip hop and Japanese national subjectivity, doctoral dissertation, University of Iowa, May, 256 pages.

Mullaney, J L (2012) "All in Time: Age and Temporality of Authenticity in the StraightEdge Music Scene.” Journal of Contemporary Ethnography 41(6): 611-635. 
Ortner S (1995) Resistance and the problem of ethnographic refusal. Comparative Studies in Society and History 37.1: 173-93.

Oware, M (2015) "We Stick Out Like a Sore Thumb...": Underground White Rappers' Underground Masculinity and Racial Evasion, Sociology of Race and Ethnicity, American Sociological Association: (2)372-86.

Perry I (2004) Prophets of the Hood: Politics and Poetics in Hip-Hop. Durham: Duke University Press.

Persley N (2015) Hip-hop theater and performance. In Justin A. Williams (ed.) The Cambridge Companion to Hip-Hop. Cambridge: Cambridge University Press.

Pieterse E. (2010). Hip-hop cultures and political agency in Brazil and South Africa. Social Dynamics 36.2: 428-47.

Ralph M (2009) Hip-Hop. Social Text 100, 27(3) (Fall): 141-146.

Rose T (2008) The Hip Hop Wars: What we Talk about When We Talk about Hip Hop And Why It Matters. New York: BasicCivitas.

Rosenberger N (2013) Dilemmas of Adulthood: Japanese Women and the Nuances of long-term Resistance. Honolulu: Hawaii University Press.

Schneidermann N (2014) 'Mic Power': 'Public' connections through the hip hop nation in Kampala. Ethnography 15(1): 88-105.

Scott J (1985) Weapons of the Weak: Everybody Forms of Peasant Resistance. New Haven and London: Yale University Press.

Vinthagen S and Johansson A (2013) 'Everyday Resistance': Explorations of a Concept and its Theories. Resistance Studies Magazine, No. 1, rsmag.org, accessed on 20 February 2018, pdfs.semanticscholar.org

Vito C (2015) Who said hip-hop was dead? The politics of hip-hop culture in Immortal Technique's lyrics. International Journal of Cultural Studies 18(4): 395-411.

Watkins S (2005) Hip Hop Matters: Politics, Pop Culture, and the Struggle for the Soul of a Movement. Boston: Beacon Press. 